\title{
The effect of proanthocyanidin-rich hulls and proanthocyanidin extracts from bean (Vicia faba L.) hulls on nutrient digestibility and digestive enzyme activities in young chicks
}

\author{
BY P. YUSTE \\ Instito de Alimentacion Animal, Cludad Universitaria, 28040 Madrid, Spain \\ AND M. LONGSTAFF \\ Department of Biological Sciences, Heriot-Watt University, Edinburgh \\ ANDC. MCCORQUODALE \\ Institute of Animal Physiology and Genetics Research, Roslin, Midlothian
}

(Received 24 September 1990 - Accepted 5 March 1991)

\begin{abstract}
Proanthocyanidins were prepared from three bean (Vicia faba $\mathbf{L}$.) varieties by extracting hulls in aqueous acetone. The amounts of freeze-dried extracts recovered were 74,89 and $97 \mathrm{~g} / \mathrm{kg}$ hull for the varieties Brunette, Statissa and Minica respectively. Chicks ( 3 weeks old) were fed on a maize-soya-bean control diet or the same control diet substituted with either $30 \mathrm{~g}$ proanthocyanidin extracts $/ \mathrm{kg}$ or $300 \mathrm{~g}$ proanthocyanidin-rich hulls $/ \mathrm{kg}$. Chicks were tube-fed diets twice daily for $4 \mathrm{~d}$. Nutrient digestibilities were calculated from amounts present in diets and freeze-dried excreta with the aid of titanium dioxide as a marker. Enzyme activities were measured in digesta removed from the jejunum. Extracts of proanthocyanidins depressed the digestibility of protein by $34 \%$, starch by $3 \%$ and had no effect on the digestibility of lipid. Proanthocyanidin-rich hulls depressed the digestibility of protein by $62 \%$, starch by $6 \%$ and lipid by $4 \%$. Digestive enzyme activities were depressed to the same extent by extracts and hulls, trypsin $(E C 3.4 .21 .4)$ by 55 and $62 \%$, $\alpha$-amylase $(E C 3.2 .1 .1)$ by 75 and $78 \%$ and lipase $(E C$ 3.1 .1 .3) by 31 and $32 \%$ for proanthocyanidin-extract and proanthocyanidin-rich-hull diets respectively. The susceptibility of substrates as well as enzymes to the effects of proanthocyanidins is discussed.
\end{abstract}

Proanthocyanidin: Nutrient digestibility: Digestive enzyme activity: Vicia faba: Chick

Proanthocyanidins have been reported to be present in appreciable amounts in many leguminous and graminaceous foods which are important in both human and animal nutrition. Fuller et al. (1966) reported that feeding high-proanthocyanidin sorghum grain resulted in reduced growth of chicks. Decreased digestibilities of crude protein (nitrogen $\times 6.25)$ and carbohydrates of high-proanthocyanidin barley have been shown to occur in chicks (Gohl \& Thomke, 1976). Eggum (1980) reported that dehulling faba (Vicia faba L.) beans improved the nutritional quality of the beans. Marquardt et al. (1977) observed that feeding chicks a diet containing $30 \mathrm{~g}$ purified proanthocyanidins from faba beans $/ \mathrm{kg}$ resulted in reduced feed intake, negative weight gains and crude fibre digestibility. Reduced amino acid, starch and lipid digestion by young chicks and adult cockerels consuming diets containing proanthocyanidin-rich bean hulls has been reported by Longstaff \& McNab (1991 a) and Longstaff et al. (1991).

One of the mechanisms whereby nutrients are rendered less digestible by proanthocyanidins is through the inactivation of digestive enzymes. Griffiths \& Moseley (1980) showed that the activities of trypsin $(E C$ 3.4.21.4) and $\alpha$-amylase $(E C$ 3.2.1.1) were 
lowered in rat digesta after ingestion of diets containing proanthocyanidin-rich bean hulls. Nitsan (1971) reported slightly reduced trypsin and greatly reduced $\alpha$-amylase levels in both intestine and pancreas of rats fed on whole faba beans compared with those fed on dehulled beans. Horigomé et al. (1988) also reported reduced activities of trypsin and $\alpha$-amylase in rat digesta after the consumption of proanthocyanidin extracts from browse plants. Longstaff \& $\mathrm{McNab}(1991 \mathrm{a})$ reported a decrease in activities of trypsin, $\alpha$-amylase and lipase (EC 3.1.1.3) in chick digesta after consumption of diets containing proanthocyanidin-rich hulls, and $\alpha$-amylase activity in the pancreas was also shown to be reduced.

Stimulatory effects of proanthocyanidins on digestion and digestive enzyme activities have also been observed. Marquardt et al. (1977) reported an increased lipid digestion in chicks and both Griffiths \& Moseley (1980) and Horigomé et al. (1988) reported increased lipase activity in digesta from rats consuming proanthocyanidins. Although most bovine rumen microbial enzymes were found to be lowered after the ingestion of oak (Quercus incana) leaves, Makkar et al. (1988) found that the activity of glutamate ammonia ligase (EC 6.3.1.2) was enhanced. Mole \& Waterman (1985) reported a stimulatory effect of quebracho on in vitro hydrolysis of bovine serum albumin by trypsin. Longstaff \& $\mathrm{McNab}$ $(1991 b)$ reported a stimulatory effect of proanthocyanidin-rich bean hulls on chick digesta lipase activity when hulls were fed at a low dietary concentration, and an inhibitory effect on digesta lipase at higher concentrations.

The purpose of the present study was to compare the effects on nutrient digestion and digestive enzyme activities of feeding chicks diets composed of semi-purified proanthocyanidin extracts at concentrations similar to or slightly higher than those present in diets composed of proanthocyanidin-rich hulls.

\section{MATERIALS AND METHODS \\ Preparation of proanthocyanidin extracts}

Pure hulls $(300 \mathrm{~g})$ from each of the three bean varieties Brunette, Statissa and Minica were weighed out into three separate 51 flasks and 21 aqueous acetone (acetone-water; 75:25 $\mathrm{v} / \mathrm{v}$ ) was added. The contents were mixed and left for $21 \mathrm{~h}$ with occasional mixing. Proanthocyanidins extracted into aqueous acetone were filtered through a large Buchner funnel with the aid of suction and the hulls re-extracted for $2 \mathrm{~h}$ in $1.5 \mathrm{l}$ aqueous acetone. Extracts were again filtered and hulls re-extracted for a further $2 \mathrm{~h}$ in $1.5 \mathrm{l}$ aqueous acetone. Finally, the extracts were filtered and the hulls washed with $500 \mathrm{ml}$ aqueous acetone. The extracts from the same hull varieties were combined, rotary evaporated to about $200 \mathrm{ml}$ and the concentrated solution frozen at $-20^{\circ}$, freeze-dried and weighed. Starting times for the extraction of proanthocyanidins from the different hull varieties were staggered to ensure that all varieties received the same time in the extraction medium. This process was repeated twice more so that a total of $900 \mathrm{~g}$ hulls from each of the three varieties were extracted.

\section{Diets}

The basal diet used in the present study was a normal chick starter diet based on maize and soya-bean meal as reported by Longstaff \& $\mathrm{McNab}(1991 \mathrm{~b}$ ). To every $\mathrm{kg}$ basal diet $2 \mathrm{~g}$ titanium dioxide was added as a digestive marker, and $40 \mathrm{~g}$ additional maize oil was added to facilitate the measurement of lipid digestion. This diet was designated the control diet. Extracts were incorporated into the control diet at $30 \mathrm{~g} / \mathrm{kg}$ inclusion and hulls at $300 \mathrm{~g} / \mathrm{kg}$ inclusion. The seven diets were as follows : control, control-Brunette extract $(970: 30, \mathrm{w} / \mathrm{w})$, control-Statissa extract $(970: 30, \mathrm{w} / \mathrm{w})$, control-Minica extract $(970: 30$, w/w), controlBrunette hulls $(700: 300, \mathrm{w} / \mathrm{w})$, control-Statissa hulls $(700: 300, \mathrm{w} / \mathrm{w})$, control-Minica hulls $(700: 300, \mathrm{w} / \mathrm{w})$. 


\section{Allocation of diets, feeding protocol and excreta collection}

Seventy 3-week-old male broiler chicks were selected as the middle weight range from a batch of 100 which had been reared in a tiered battery brooder. Chicks were weighed individually, randomized into seven groups of equal average weight and were housed in individual cages equipped for quantitative collection of excreta in a room with a controlled environment with $23 \mathrm{~h}$ light $/ \mathrm{d}$. Each of the seven diets was tube-fed to ten chicks. On day I after withdrawal of food for $6 \mathrm{~h}$, chicks were tube-fed $15 \mathrm{~g}$ of the appropriate diet at approximately $15 \cdot 30$ hours. On days 2 and 3 chicks were tube-fed $15 \mathrm{~g}$ diet at approximately $08 \cdot 30$ and 15.30 hours. On day 4 chicks were tube-fed $15 \mathrm{~g}$ diet at 08.30 hours. During the afternoon of day 2 clean trays were placed under each cage and the excreta voided over the subsequent $48 \mathrm{~h}$ were collected, frozen at $-20^{\circ}$, freeze-dried and kept for nutrient digestibility measurements. Throughout the experiment chicks were allowed free access to water.

\section{Collection of digesta}

Chicks were killed by intravenous injection of sodium pentobarbitone starting at 13.00 hours on day 4. Digestive tracts were removed and the contents of the jejunum (digesta) were gently squeezed out into separate vials, mixed thoroughly and kept frozen in liquid nitrogen during the period of collection. Thereafter, vials were transferred to a freezer at $-20^{\circ}$ until digesta were required for enzyme measurements.

The jejunum of some chicks provided very little digesta. In these instances it was found that not every enzyme analysis could be performed. For the $\alpha$-amylase and lipase assays digesta from six chicks per diet were chosen for analysis and in the case of trypsin the following diets: control, Brunette, Statissa, Minica (hulls) and Brunette, Statissa, Minica (extracts) provided nine, nine, six, six, seven, seven and five digesta samples respectively.

\section{Measurement of digesta enzyme activities}

Digesta $(400 \mathrm{mg}$ ) while still frozen were quickly weighed into test-tubes kept on ice and $6 \mathrm{ml}$ ice-cold physiological saline $(9 \mathrm{~g}$ sodium chloride/l) was added. The contents were mixed thoroughly and tubes placed in a refrigerator at $4^{\circ}$ for $1 \mathrm{~h}$. The contents were remixed and then centrifuged at $2000 \mathrm{~g}$. Portions of supernatant fractions containing enzymes were assayed for trypsin, $\alpha$-amylase and lipase activities as previously described by Longstaff $\&$ McNab (1991 a). The method for trypsin activity was based on that of Erlanger et al. (1961) using the synthetic substrate $N$-benzoyl-DL-arginine- $p$-nitroaniline (BAPNA). The method for $\alpha$-amylase activity was based on that of Lever (1972) for the detection of glucose released from pregelatinized maize starch used as substrate. Lipase activity was measured using the diagnostic kit no. 800 (Sigma Chemical Co). In this titration method the amount of sodium hydroxide required to neutralize the fatty acids released from olive-oil triacylglycerols is proportional to lipase activity.

\section{Measurement of starch, lipid and amino acids}

Starch, lipid and amino acids were measured in the diets and excreta as previously described (Longstaff \& McNab 1991a), starch according to the method of Lever (1972), lipid by the European Communities (1971) procedures and amino acids as described by Blair et al. (1981). Total protein digestibilities were calculated from the sum of amino acids in diets and excreta.

\section{Statistical methods}

The observations on digestibility had distributions whose variances tended to increase as the means decreased. Transformations often associated with observations which are percentages (logistic, angular and complementary log) were not successful in stabilizing the 
variance in these observations. Contrasts among the diet means were calculated on the percentage scale and estimates of their standard errors were calculated using the variances observed only in the diet groups involved in the contrast (as described by Snedecor \& Cochran, 1973). An approximation to Student's $t$ test (from Satterthwaite, 1946) was used to determine the statistical significance of the contrasts. This involved using reduced degrees of freedom which depended on the degree of heterogeneity in the observed variances. The statistical significance of the variety and variety $\times$ source interaction was established by the analysis of variance between the six experimental diets on the percentage scale. As replication was equal in the diet groups (apart from one missing observation on the digestibility of starch), comparing the variance ratios associated with the effects with $F$ distributions should give acceptable significance probabilities despite differences in variance (Scheffé, 1959).

The observations on enzyme activity had distributions whose standard deviations were approximately proportional to the means. The observations were transformed to the logarithmic scale and this was successful in removing much of the dependence of the variance on the mean. Analysis of variance between diets or the equivalent multiple regression in variates where observations were missing were then performed to estimate the common variance and to assess the statistical significance of the variety and source $\times$ variety interaction in the transformed scale. Contrasts between the diet means were calculated on the logarithmic scale and their standard errors were estimated using the estimate of common variance. Student's $t$ tests were then used to determine the statistical significance of these contrasts.

\section{RESULTS}

The amounts of freeze-dried proanthocyanidins obtained from the three varieties of hulls after each extraction are shown in Table 1. The Minica hulls possessed the most, Statissa less and Brunette the least amount of proanthocyanidins.

The influence of proanthocyanidin extracts and proanthocyanidin-rich hulls on digestive enzyme activities are shown in Table 2 . All three digestive enzymes were most active when chicks were fed on the control diet. Extracts reduced the activity of trypsin in digesta from 1923 to $861 \mu \mathrm{g}$ nitroaniline (a reduction of $55 \%$ ), the activity of $\alpha$-amylase the most from 141.8 to $34.9 \mathrm{mg}$ maltose (a reduction of $75 \%$ ), and the activity of lipase the least from 68.0 to 46.6 Sigma-Tietz units (a reduction of $31 \%$ ). Hulls reduced the activity of trypsin from 1923 to $723 \mu \mathrm{g}$ nitroaniline (a reduction of $62 \%$ ), the activity of $\alpha$-amylase the most from 141.8 to $30.9 \mathrm{mg}$ maltose (a reduction of $78 \%$ ), and the activity of lipase the least from 68.0 to 46.3 Sigma-Tietz units (a reduction of $32 \%$ ). There were no significant differences between the effect of extracts and hulls, nor between different varieties.

The influence of proanthocyanidin extracts and proanthocyanidin-rich hulls on nutrient digestibilities is shown in Table 3. Digestibilities of all three nutrients were greatest when chicks were fed on the control diet. Extract diets reduced the digestibilities of all three nutrients significantly less than hulls. The digestibility of protein fell by 34 and $62 \%$, starch by 3 and $6 \%$ and lipid by 0 and $4 \%$ for extract and hull diets respectively. There were no significant differences, however, in the way the different varieties exerted their effects.

\section{DISCUSSION}

It would appear that the amount of proanthocyanidins extracted with aqueous acetone and measured gravimetrically from the three varieties of hulls was in fairly good agreement with that obtained previously (Longstaff et al. 1991). In the previous study the proanthocyanidins extracted into aqueous acetone and quantified colorimetrically using a purified bean proanthocyanidin, by both the vanillin-glacial acetic acid method of Butler et al. 
Table 1. Weight of proanthocyanidins extracted by aqueous acetone from three varieties of bean (Vicia faba L.) hulls

\begin{tabular}{llll}
\hline \hline & \multicolumn{3}{c}{ Proanthocyanidins $(\mathrm{g})$} \\
\cline { 2 - 4 } \cline { 3 - 4 } & Brunette & Statissa & Minica \\
\hline Variety ... & & & \\
Hulls $(\mathrm{g})$ & $22 \cdot 5$ & $26 \cdot 8$ & $29 \cdot 1$ \\
300 & $21 \cdot 7$ & $26 \cdot 1$ & $28 \cdot 7$ \\
300 & $22 \cdot 0$ & $27 \cdot 0$ & $29 \cdot 3$ \\
300 & $22 \cdot 1$ & $26 \cdot 6$ & $29 \cdot 0$ \\
Mean & $0 \cdot 4$ & $0 \cdot 5$ & $0 \cdot 3$ \\
SD & 74 & 89 & 97 \\
Proanthocyanidin (g/kg hulls) & & & \\
Mean & 2 & 2 & 1 \\
SD & & & \\
\hline \hline
\end{tabular}

(1982) and the anthocyanidin formation method of Porter et al. (1986), were reported to be 78 and $82 \mathrm{~g} / \mathrm{kg}, 78$ and $69 \mathrm{~g} / \mathrm{kg}$ and 104 and $87 \mathrm{~g} / \mathrm{kg}$ hulls for the varieties Brunette, Statissa and Minica respectively. It would appear, therefore, that the semi-purified aqueous extracts obtained gravimetrically in the present study, 74,89 and $97 \mathrm{~g} / \mathrm{kg}$ for Brunette, Statissa and Minica respectively, contained very little material that was not proanthocyanidins.

Proanthocyanidin extracts and hull diets greatly inhibited all three digestive enzyme activities, yet in the case of $\alpha$-amylase and lipase this inhibition was not accompanied by as great a reduction in starch and lipid digestion as anticipated. Presumably digestive enzymes are present in excessive amounts and the breakdown of starch and lipid can still take place at suboptimal levels of these enzymes. A considerable reduction in protein digestion did, however, accompany a reduction in trypsin activity and in this particular instance proanthocyanidins may also have been reacting directly with proteins themselves. Consequently it would appear that proanthocyanidins may have less affinity for the substrates starch and lipid.

It is difficult to explain the similar effect of hull and extract diets on digestive enzyme activities and the different effect of these diets on nutrient digestion. The lowered nutrient digestion obtained with the hull diets might have been thought to arise as a consequence of lower enzyme activities in the digestive tract. One may question, therefore, whether the activities of enzymes measured after dilution in vitro are indeed representative of their actual activity in the digestive tract. The greater impairment of digestion with the hull diets cannot be explained by the presence of the hulls per se, since the deleterious effects on digestion of proanthocyanidin-free hulls is small (Longstaff \& McNab 1991 ; Longstaff et al. 1991) and would not account for the $28 \%$ difference in protein digestion between hull and extract diets. Although hulls were included at a dietary concentration of $300 \mathrm{~g} / \mathrm{kg}$ providing the proanthocyanidin equivalent of diets composed of $30 \mathrm{~g}$ extract $/ \mathrm{kg}$ it is unlikely that the proanthocyanidins in the hull diets would have been solubilized to the same extent as in the extract diets during passage through the digestive tract. This might indicate that insoluble proanthocyanidins might be capable of adsorbing proteins from solution as suggested by Bate-Smith $(1973,1975)$. Alternatively, the excessive bulk of the digesta containing hulls may have slowed down its rate of transit permitting the release of proanthocyanidins over a longer period and an interaction with substrates over a larger area of digestive tract. 


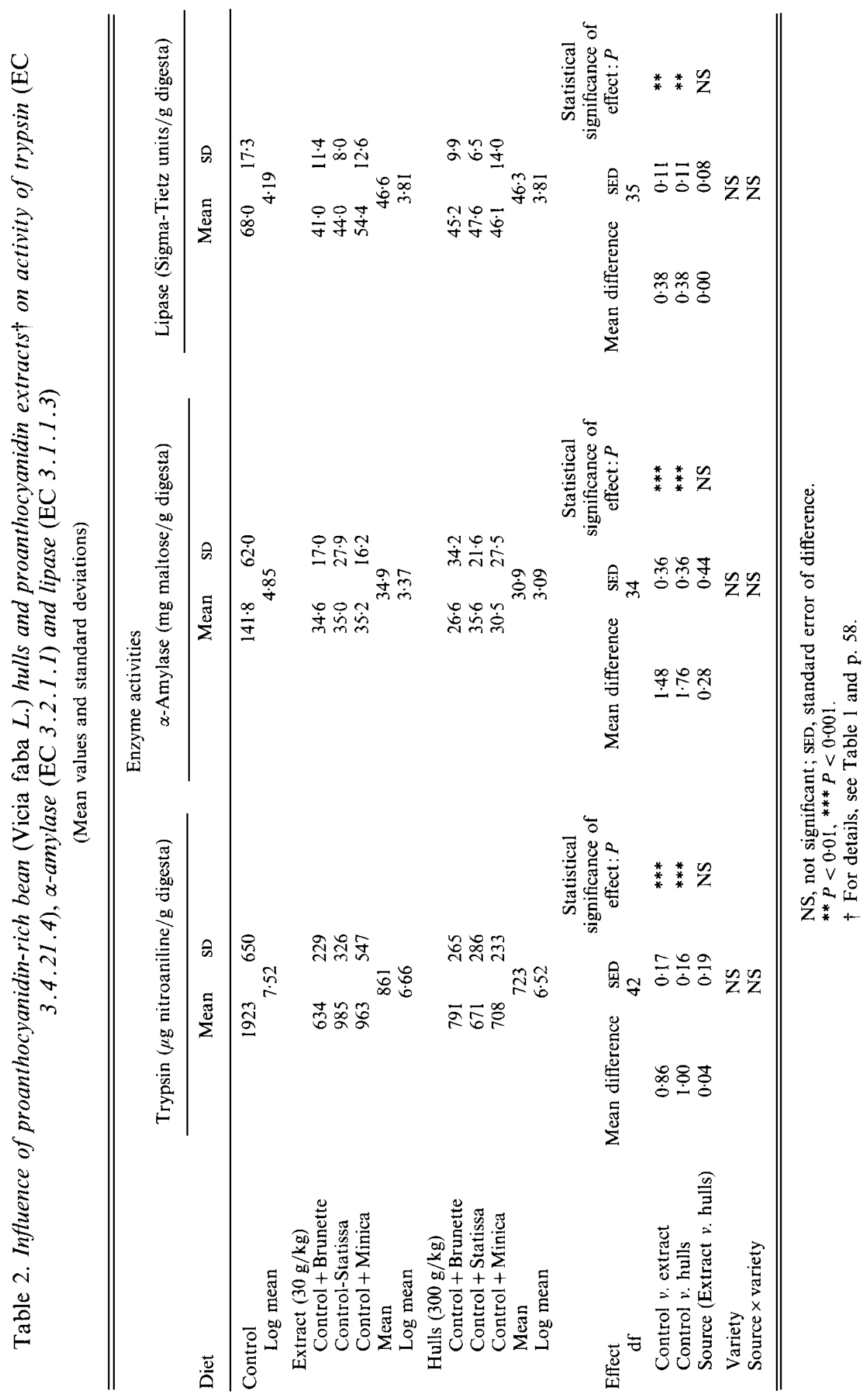


PROANTHOCYANIDINS IN YOUNG CHICKS

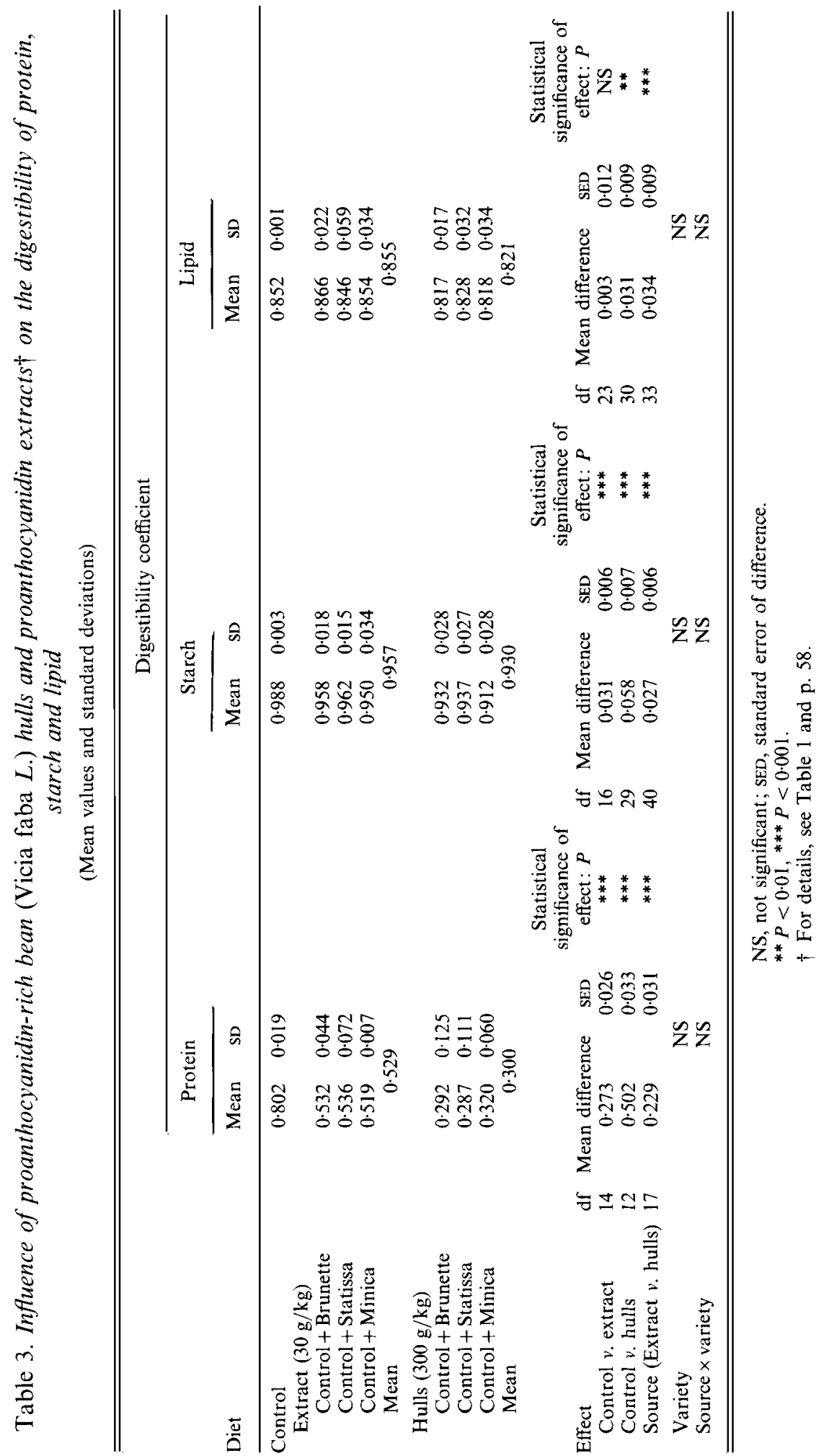


It is acknowledged that diets containing hulls and extracts are not strictly comparable since many fewer digestible nutrients, especially protein, were available to chicks when hull diets were ingested. The effect of the different diets on the population of caecal microflora is not known. However, it is unlikely that differences in microflora population would contribute markedly to differences in nutrient digestion since Longstaff et al. (1991 a) reported no difference in nutrient digestion between caecectomized and intact cockerels and Parsons (1985) noted an increase of only a few percent in amino acid digestion by intact compared with caecectomized cockerels.

Proanthocyanidins in the present study did not reduce nutrient digestion as much as previously reported (Longstaff \& McNab $1991 \mathrm{a}$ ) when diets containing higher levels of proanthocyanidin-rich hulls $(400 \mathrm{~g} / \mathrm{kg})$ caused a severe decrease in nutrient digestion. Consequently, the more moderate effect in the present study may have prevented differences being detected between bean varieties. No stimulatory effect of proanthocyanidins on lipase activity or lipid digestion was observed, contrary to reports by Griffiths \& Moseley (1980) and Marquardt (1977) respectively with rats. It may be only at lower levels of proanthocyanidin ingestion that stimulation of lipolysis occurs since Griffiths and Moseley (1980) fed proanthocyanidin-rich hulls at $100 \mathrm{~g} / \mathrm{kg}$ dietary inclusion and Longstaff $\&$ McNab $(1991 b)$ reported an increased lipase activity only when proanthocyanidin-rich bean hulls were fed at a dietary inclusion of 20 and $50 \mathrm{~g} / \mathrm{kg}$ to chicks.

Although many puzzling features about the action of proanthocyanidins remain, the present study has shown that the anti-nutritional property of the hulls is due to their proanthocyanidin content and that these polyphenolics reduce nutrient digestion by inactivation of digestive enzymes and possibly also by rendering dietary protein unavailable.

The authors thank Kim Henderson for her help with the feeding of the chicks.

\section{REFERENCES}

Bate-Smith, E. C. (1973). Tannins of herbaceous leguminosae. Phytochemistry 12, 1809-1812.

Bate-Smith, E. C. (1975). Phytochemistry of proanthocyanidins. Phytochemistry 14, 1107-1113.

Blair, J. C., Harber, C. D., McNab, J. M., Mitchell, G. G. \& Scougall, R. K. (1981). Analytical Data of Poultry Feedstuffs. Agricultural Research Council's Poultry Research Centre, Occasional Publication no. 1, pp. 7-8.

Butler, L. G., Price, M. C. \& Brotherton, J. E. (1982). Vanillin assay for proanthocyanidins (condensed tannins): Modification of the solvent for estimation of the degree of polymerisation. Journal of Agricultural Food Chemistry 30, 1087-1089.

Eggum, B. O. (1980). Factors affecting the nutritional value of field beans (Vicia faba). In Vicia faba. Feeding Value, Processing and Viruses, pp. 107-123. [D. A. Bond, editor]. Brussels and Luxembourg: Nijhoff.

Erlanger, B. F., Kokowsky, N. \& Cohen, W. (1961). The preparation and properties of two new chromogenic substrates of trypsin. Archives of Biochemistry and Biophysics 95, 271-278.

European Communities (1971). IV. Determination of crude oils and fats. Process A, Part 18. Animal Feeding stuffs. pp. 15-19. London: H.M. Stationery Office.

Fuller, H. L., Potter, D. K. \& Brown, A. R. (1966). The feeding value of grain sorghum in relationship to their tannin content. Georgia Agriculture Experimental Station Technical Bulletin no. NS 176, pp. 5-14. Athens: Georgia Agriculture Experimental Station.

Gohl, B. \& Thomke, S. (1976). Digestibility coefficients and metabolizable energy of barley diets for layers as influenced by geographical area of production. Poultry Science 55, 2369-2374.

Griffiths, D. W. \& Moseley, G. (1980). The effect of diets containing field beans of high and low polyphenolic content in the activity of digestive enzymes in the intestine of rats. Journal of the Science of Food and Agriculture 31, $255 \cdots 259$.

Horigomé, T., Kumar, R. \& Okamoto, K. (1988). Effects of condensed tannins prepared from leaves of fodder plants on digestive enzymes in vitro and in the intestine of rats. British Journal of Nutrition 60, $275-285$.

Lever, M. (1972). A new reaction for colorimetric determination of carbohydrates. Analytical Biochemistry 47, 273-279.

Longstaff, M. \& MeNab, J. M. (1991 $a$ ). The inhibitory effects of hull polysaccharides and tannins of field beans (Vicia faba L.) on the digestion of amino acids, starch and lipid and on digestive enzyme activities in young chicks. British Journal of Nutrition 65, 199-216.

Longstaff, M. \& McNab, J. M. (1991b). The effect of concentration of tannin-rich field bean hulls (Vicia faba L.) 
on activities of lipase (EC 3.1.1.3) and $\alpha$-amylase $(E C$ 3.2.1.1) in digesta and pancreas and on the digestion of lipid and starch by young chicks. British Journal of Nutrition 66, 139-147.

Longstaff, M., McBain, B. \& McNab, J. M. (199I). The antinutritive effect of proanthocyanidin-rich and proanthocyanidin-free hulls from field beans of TME and on protein, starch and lipid digestion by intact and caecectomised cockerels. Animal Feed Science and Technology 34, 147-161.

Makkar, H. P. S., Singh, B. \& Dawra, R. K. (1988). Effect of tannin-rich leaves of oak (Quercus incana) on various microbial enzyme activities of the bovine rumen. British Journal of Nutrition 60, 287-296.

Marquardt, R. R., Ward, A. T., Campbell, L. D. \& Cansfield, P. E. (1977). Purification identification and characterization of a growth inhibitor in faba beans (Vicia faba L. var. minor). Journal of Nutrition 107, 1313-1324.

Mole, S. \& Waterman, P. G. (1985). Stimulatory effects of tannins and cholic acid on tryptic hydrolysis of proteins: ecological implications. Journal of Chemical Ecology 11, 1323-1332.

Nitsan, Z. (1971). Vicia faba beans vs. soybean meal as a source of protein. Journal of the Science of Food and Agriculture 22, 252 255.

Parsons, C. M. (1985). Influence of caecectomy on digestibility of amino acids by roosters fed distillers' dried grains with solubles. Journal of Agricultural Science, Cambridge 104, 469-472.

Porter, L. J., Hostich, L. N. \& Chan, B. G. (1986). The conversion of procyanidins and prodelphinidins to cyanidin and delphinidin. Phytochemistry 25, 223-230.

Satterthwaite, F. E. (1946). An approximate distribution of estimates of variance components. Biometrics Bulletin 2, 110.

Scheffé, H. (1959). The Analysis of Variance. New York: John Wiley and Son.

Snedecor, G. N. \& Cochran, W. G. (1973). Statistical Methods, 6th ed., p. 234. Ames, Iowa: Iowa State University Press. 